\title{
MICRO-ORGANISMOS PROBIÓTICOS: CARACTERIZAÇÃO DE LINHAGENS E SEUS EFEITOS NO HOSPEDEIRO
}

\begin{abstract}
Esta revisão teve como objetivo divulgar os principais critérios de segurança para caracterização de linhagens probióticas, abordados por orgãos reguladores como a Organização das Nações Unidas para Alimentação e Agricultura e a Organização Mundial de Saúde. Também discutiu-se a importância de linhagens probióticas e os mecanismos de ação atribuídos a esses micro-organismos sobre a saúde do hospedeiro. Sugere-se que esse material também seja utilizado como referência, a fim de padronizar a caracterização de linhagens probióticas usadas na indústria alimentos. A comunidade científica e indústrias que aplicam probióticos em seus produtos buscam selecionar linhagens cada vez mais específicas às necessidades fisiológicas do hospedeiro, portanto, a padronização dessas linhagens, a condução de ensaios clínicos, bem como a compreensão dos fenômenos envolvidos na interação hospedeiroprobiótico tornaram-se importantes desafios.
\end{abstract}

* Doutora em Ciência de Alimentos, Docente, Mestrado em Ciência e Tecnologia do Leite e Derivados, Universidade Norte do Paraná, Londrina, Paraná, Brasil (e-mail: gcnobre@gmail.com, giselle.nobre@ unopar.br).

* Doutora em Ciência de Alimentos, Docente, Departamento de Ciência e Tecnologia de Alimentos, Centro de Ciências Agrárias, Universidade Estadual de Londrina, Londrina, Paraná, Brasil (e-mail: luciah@uel.br). 


\section{INTRODUÇÃO}

Muitos estudos clínicos abordam os efeitos de micro-organismos probióticos sobre a microbiota do trato gastrointestinal (TGI) e a saúde do hospedeiro.

Tendo em vista a popularidade dos alimentos probióticos e o aumento substancial de sua divulgação, a comunidade científica e as indústrias de alimentos e de fármacos estão dedicando especial atenção à identificação de linhagens, cujas características sejam potencialmente probióticas. Cada grupo de pesquisas vem adotando diferentes abordagens nessa busca, tanto para identificação de linhagens cuja diferenciação pode ser muito tênue na mesma espécie, quanto para caracterização dos seus efeitos que em geral são linhagens específicas (GUEIMONDE e SALMINEM, 2006).

Visando uniformizar a caracterização de linhagens, a Organização das Nações Unidas para Alimentação e Agricultura (FAO) e a Organização Mundial de Saúde (WHO) estabeleceram comitês, cujas discussões geraram diretrizes que visam regulamentar a caracterização de micro-organismos potencialmente probióticos (FAO, 2002). Os órgãos reguladores de grupos de países (em conjunto ou individualmente), como o Mercado Comum do Sul (MERCOSUL) na América Latina e a Agência Nacional de Vigilância Sanitária (BRASIL, 2008), também buscam regulamentar o uso desses organismos e/ou de produtos que os contenham visando garantir a segurança do consumidor, bem como a comprovação clínica dos efeitos esperados no hospedeiro.

Esta revisão de literatura teve como objetivo divulgar os critérios para caracterização de linhagens probióticas, propostos pela Organização das Nações Unidas para Alimentação e Agricultura (FAO) e a Organização Mundial de Saúde (WHO). Também foram discutidos alguns mecanismos de ação envolvendo micro-organismos probióticos e seus efeitos no organismo humano.

\section{DIRETRIZES PARA CARACTERIZAÇÃO E APLICAÇÃO DE MICRO-ORGANISMOS PROBIÓTICOS}

Na caracterização de micro-organismos probióticos, bem como no estudo do seu modo de ação, é imprescindível a identificação precisa desses organismos. De acordo com as recomendações da FAO/WHO (FAO, 2002), o micro-organismo potencialmente probiótico deve ser avaliado e apresentar algumas características fundamentais (Esquema 1). Dentre essas características destacam-se: a definição da origem e identificação do micro-organismo; sua inoquidade; resistência a ambientes inóspitos, e propriedades tecnológicas que propiciem sua viabilidade em quantidade suficiente para promover efeitos benéficos na saúde do hospedeiro (GUEIMONDE e SALMINEM, 2006; COLLINS, LACROIX e YILDIRIM, 2007).

O produto probiótico confiável exige a correta identificação da espécie bacteriana utilizada. Os métodos empregados para essa finalidade são baseados em técnicas fenotípicas convencionais, sendo aconselhado o uso de abordagens moleculares, o que permite a classificação taxonômica precisa. A validação do método torna-se importante, pois as investigações sugerem que muitos dos efeitos atribuídos ao probiótico são específicos de cada linhagem, de modo que estudos com uma espécie ou linhagem não podem ser extrapolados para outras, mesmo aquelas estreitamente relacionadas (GUEIMONDE e SALMINEM, 2006; FAO, 2002).

Os micro-organismos probióticos devem ser resistentes ao estresse ambiental e ao ambiente gastrointestinal, além de apresentar habilidade de crescimento in vitro com baixa ou nenhuma taxa de ocorrência de mutações. Os estudos que avaliam a resistência de linhagens potencialmente probióticas aos sucos gástrico, pancreático e à bile, têm sido conduzidos in vitro, geralmente utilizando suco gástrico artificial, bile suína ou bovina e extrato de pâncreas de vários animais (CONWAY, GORGABCH e GOLDIN, 1987). A tolerância às condições de estresse fisiológico pode assegurar a funcionalidade após a ingestão (LANKAPUTHRA e SHAH, 1995; BEGLEY, HILL e GAHAN, 2006; DEL PIANO et al. 2006).

A viabilidade e estabilidade de micro-organismos probióticos são parâmetros fundamentais 
às alegações funcionais e devem ser previstas, sobretudo, nas etapas de seleção e processamento do probiótico, já que diversos fatores afetam essa condição até que o micro-organismo alcance o local alvo no hospedeiro (LACROIX e YILDIRIM, 2007).

-

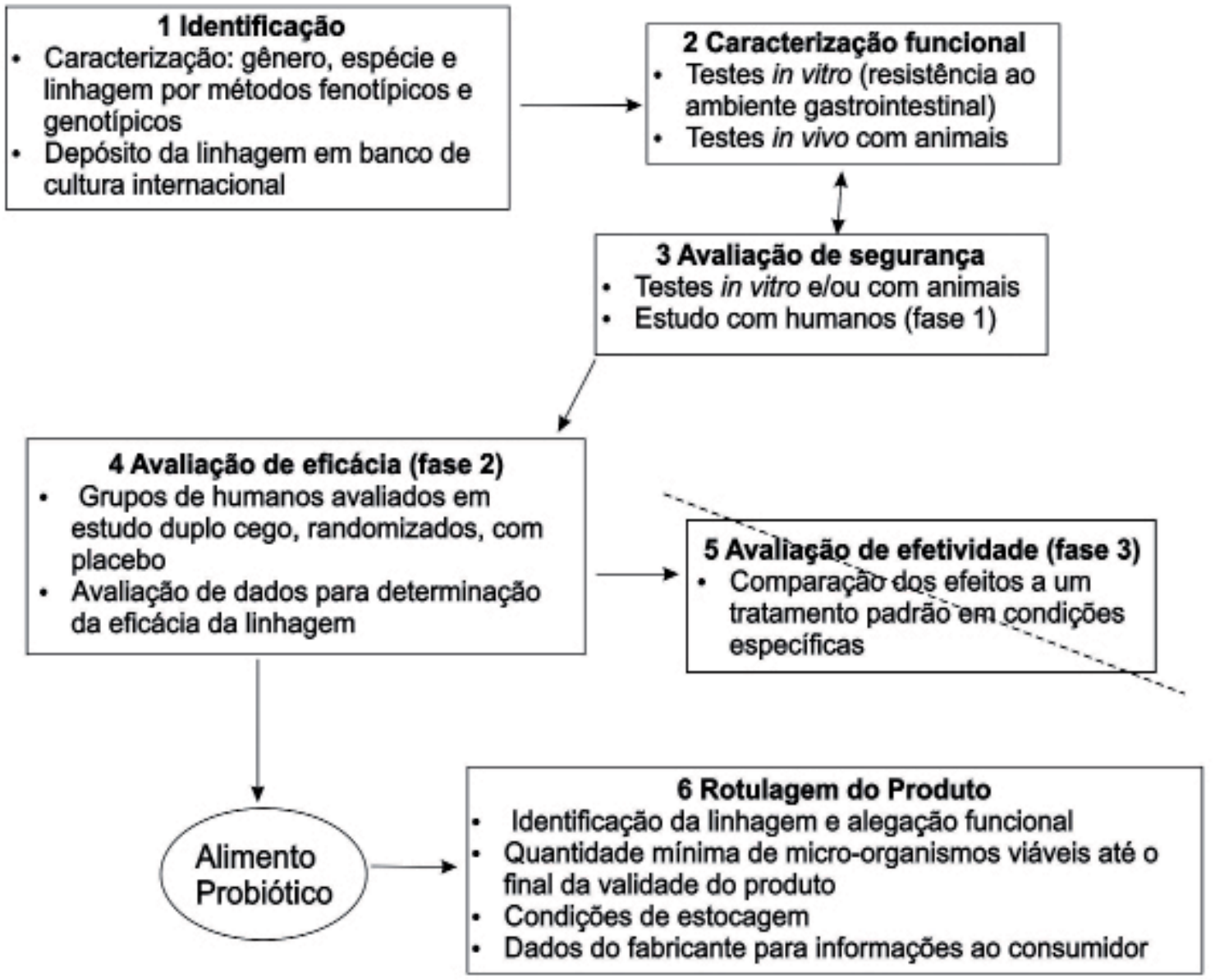

\section{ESQUEMA 1 - DIRETRIZES PARA CARACTERIZAÇÃO DE MICRO-ORGANISMOS PROBIÓTICOS PARA USO EM ALIMENTOS}

Adaptado de FAO (2002). O item 5 geralmente não se aplica a alimentos e sim a fármacos probióticos.

A falta de procedimento padrão para avaliação da tolerância ao TGI dificulta a comparação entre linhagens. Embora, a resistência a sais biliares in vitro tenha correlação direta com a sobrevivência no TGI in vivo, a positividade nesses testes não é suficiente para caracterizar o microorganismo como probiótico e, em geral, são recomendados testes in vivo (CONWAY, GORGABCH e GOLDIN, 1987; FAO, 2002).

Em estudos envolvendo probióticos, Del Piano e colaboradores (2006 e 2008) investigaram a resistência de algumas linhagens de lactobacilos a secreções gastrointestinais artificiais e de origem humana, obtidas em procedimentos clínicos. Observaram que menos de $20 \%$ das bactérias sobreviveu após 1 hora da exposição ao suco gástrico simulado. Usando o suco gástrico humano foi verificada taxa de sobrevivência entre $15 \%$ e $45 \%$. Quanto à bile, as linhagens foram claramente mais sensíveis à bile bovina comparada aos sais de bile humana. A sensibilidade ao suco pancreático varia em função do tempo de exposição, não havendo diferença significativa entre o suco pancreático simulado e o humano. Desse modo, tais autores propuseram a utilização de secreções humanas na avaliação da resistência de probióticos ao TGI.

Probióticos devem ter status Generally Recognized as Safe (GRAS). Ainda que a 
recomendação da FAO seja para avaliação de toda e qualquer linhagem com finalidade de uso probiótico, os dados necessários para analisar a segurança desses micro-organismos podem variar, dependendo da espécie de interesse, da intenção de aplicação e/ou da população alvo. Historicamente, lactobacilos e bifidobactérias associados a alimentos têm sido considerados seguros (ADAMS e MARTEAU, 1995). Entretanto, quando não há histórico de uso seguro, são exigidos estudos pré-clínicos extensivos, incluindo avaliação da toxicidade conforme definido no Manual para ensaios com produtos químicos - 408 da OECD (1998), além de estudos clínicos que demonstrem a tolerabilidade da população alvo (JANKOVIC et al., 2010).

A literatura reporta alguns casos de infecções sistêmicas relacionadas ao consumo de produtos probióticos comerciais (FAO, 2002). Embora todos esses casos estejam associados a pacientes em condições médicas subjacentes, a comunidade científica está buscando meios para suprimir essas ocorrências. Além disso, verifica-se preocupação relacionada a linhagens de Enterococcus resistentes à vancomicina e outros micro-organismos multi-resistentes às terapias antibióticas, uma vez que é possível transferir plasmídeos de resistência para micro-organismos inócuos (COURVALIN, 2006). Os micro-organismos probióticos devem exibir tolerância a substâncias antimicrobianas utilizadas na prática clínica, entretanto não devem ser capazes de transmitir o fator de resistência a outros micro-organismos (DEL PIANO et al., 2006).

Os testes de segurança são, em geral, aplicados em três fases que compreendem a inocuidade do micro-organismo, sobretudo no que concerne a infecções sistêmicas, atividades metabólicas deletérias e excessiva estimulação do sistema imune em indivíduos suscetíveis. Em seguida, avalia-se a sua eficácia com base nos efeitos observados em grupos de indivíduos comparados ao grupo controle, preferencialmente em grupos duplo cego randomizado com placebo que visam a comprovação biológica e estatística dos efeitos inerentes ao micro-organismo utilizado. Verifica-se, então, sua eficiência mediante comparação dos efeitos do probiótico com relação a tratamento padrão sob condição específica. Essa fase geralmente não é aplicada a alimentos probióticos (item 5 do Esquema 1). Com relação ao consumo de probióticos em alimentos não pode haver efeito adverso, devendo ser relatada e monitorada a ocorrência de qualquer efeito colateral na fase de avaliação de segurança (FAO, 2002). Esses micro-organismos devem se manter viáveis no produto durante e após o processamento, o transporte e a estocagem, além de apresentar estabilidade que garanta efeito benéfico quando consumidos. A inclusão de micronutrientes e o uso de parâmetros como a atividade de água, temperatura, $\mathrm{pH}$, pressão osmótica, concentração de oxigênio e estresse mecânico, também influenciam sua estabilidade (DEL PIANO et al., 2006). Além disso, deve ser avaliado o uso de embalagens que atendam essas características no acondicionamento do produto final.

A manutenção de células probióticas com alta viabilidade pode ser obtida pela adição de substâncias com o objetivo de proteger as células contra injúrias provocadas pelos processamentos. Compostos como leite, nitrogênio não proteico, hidrolisado proteico de soro de leite, L-cisteína e alguns prebióticos ou carboidratos simples podem incrementar a sobrevivência de probióticos, além de melhorarem o processo digestivo (SAVINE et al., 2010; SARKAR, 2010).

Dave e Shah (1998) observaram que a aplicação de cisteína, concentrado proteico do soro de leite e hidrolisado ácido de caseína ou triptona, protege as células de Bifidobacterium longum, melhorando sua viabilidade. Recomendaram também L- cisteína como fator de proteção em células de $L$. acidophilus. Savini e colaboradores (2010) avaliaram vários agentes crioprotetores na viabilidade de linhagens de Lactobacillus rhamnosus liofilizados. Observaram que a glicerina estabilizou e o manitol aumentou a viabilidade das bactérias, mesmo de células estocadas por cinco meses à temperatura ambiente, quando comparado ao processo sem agentes protetores. Já, Guergoletto et al. (2010) observaram maior viabilidade de L. casei LC1 aderido à fibra vegetal quando utilizaram trealose como agente protetor no processo de secagem a vácuo.

As interações entre micro-organismos devem ser consideradas, tanto na produção de alimentos como em quaisquer produtos contendo mais de uma linhagem. Exemplo de interação 
desfavorável ocorre com a presença de $\mathrm{O}_{2}$ livre, que no metabolismo de algumas bactérias desencadeia a ativação do sistema lactoperoxidase. Esse sistema, tido como fator antimicrobiano natural do leite, na presença de lactoperoxidase, $\mathrm{H}_{2} \mathrm{O}_{2}$ e tiocianato resulta nos ácidos hipotiociânico e hipotiocianato. Esses compostos atuam como antimicrobianos ativos e podem inibir, tanto espécies indesejadas como as espécies de interesse. Embora seja desativado pelo calor, o sistema lactoperoxidase pode ser reativado por algumas bactérias iniciadoras pela produção de $\mathrm{H}_{2} \mathrm{O}_{2}$. Sarkar e Misra (1994) relataram a inibição do crescimento das espécies em iogurte e de L. acidophilus durante a fabricação de leite fermentado, devido à reativação do sistema lactoperoxidase. Kawasaki et al. (2006) também observaram inibição de $B$. bifidum e $B$. longum em presença de altas concentrações de $\mathrm{O}_{2}$ e subsequente produção de $\mathrm{H}_{2} \mathrm{O}_{2}$. Adicionalmente, $\mathrm{o} \mathrm{H}_{2} \mathrm{O}_{2}$ intracelular pode bloquear a enzima frutose-6-fosfofrutocetolase responsável pelo metabolismo de açúcares em bifidobactérias (SARKAR, 2010). É possível controlar a produção de metabólitos que influenciam o crescimento e a viabilidade dos micro-organismos em dado ambiente e para tanto as interações entre linhagens, ou a presença de compostos que desencadeiem esses fenômenos devem ser consideradas. A escolha adequada de embalagens e/ou a adição de agentes sequestrantes de oxigênio, como o àcido ascórbico, podem ser fundamentais nesses processos (SARKAR, 2010).

A fermentação em dois estágios pode representar alternativa adequada. Lankaputhra e Shah (1995) observaram maior viabilidade de culturas probióticas quando essas foram usadas na fase inicial da fermentação seguida pelas culturas tradicionais do iogurte.

Devido às interações microbianas, muitas vezes as linhagens são selecionadas com base em propriedades tecnológicas e não na promoção de saúde (LACROIX e YILDIRIM, 2007) embora a coexistência de ambas as propriedades seja sempre desejável e mais adequada. Outro fator que afeta a viabilidade de micro-organismos probióticos está relacionado à adaptação das linhagens a condições estressantes no processo de obtenção de culturas. Para promover a adaptação e melhorar sua viabilidade tem sido usado estresse em doses subletais. Alguns autores argumentam que determinadas linhagens de bifidobactérias submetidas a esse tipo de estresse, tanto pelo aumento de temperaturas quanto pela concentração de sais, podem induzir a síntese de proteínas protetoras específicas, resultando em melhor adaptação ao meio e consequentemente maior viabilidade (SCHMIDT e ZINK, 2000; LACROIX e YILDIRIM, 2007). Saarela e colaboradores (2004) também observaram que na fase estacionária das culturas probióticas, os tratamentos subletais aumentam a sua viabilidade tanto em escala de laboratório quanto em escala industrial. Em contrapartida, adaptações a condições de estresse como efeito desses tratamentos podem levar à redução na atividade celular e, eventualmente, a alterações na funcionalidade de células probióticas no intestino, evidenciando a necessidade de se desenvolver compreensão mais aprofundada das respostas de probióticos a essas condições especiais (LACROIX e YILDIRIM, 2007).

O ambiente inóspito do trato gastrointestinal e as tecnologias empregadas para veiculação dos micro-organismos são responsáveis por flutuações populacionais, assim como pela baixa viabilidade de bactérias probióticas no organismo. É possível que a ingestão associada a alimentos proteja as bactérias durante a passagem pelo trato gastrointestinal, ou que bactérias de origem humana tenham maior tolerância às secreções (FLOCH, 2002; DEL PIANO et al., 2006, RANADHEERA, BAINES e ADAMS, 2010). Além disso, os processos de imobilização e microencapsulação vêm ganhando espaço na comunidade acadêmica e nas indústrias. Essas tecnologias melhoram a viabilidade de probióticos, bem como a ação de compostos bioativos em alimentos (TALWALKAR e KAILASAPATHY, 2003; CHAMPAGNE e FUSTIER, 2007).

Doleyers e colaboradores (2002) observaram que as células imobilizadas de B. longum em grânulos de goma gelana quadruplicaram a produção de células quando comparado à cultura de células livres. Sarkar (2010), bem como Socol e colaboradores (2010), reportaram vários estudos cujos encapsulantes protegeram os probióticos contra os efeitos do oxigênio, do congelamento, do processamento, da estocagem e das condições inóspitas do TGI (Tabela1).

A produção de probióticos em escala industrial representa desafio tecnológico, tanto 
pela obtenção de grande número de células viáveis, como pela manutenção da sua viabilidade no produto pronto para consumo. Embora a quantidade de células requeridas para produzir benefícios terapêuticos não seja conhecida e possa variar em função da linhagem e do efeito desejado à saúde, em geral tem sido recomendado o nível mínimo de $10^{6}$ células viáveis $/ \mathrm{mL}$ ou g do produto (OUWEHAND e SALMINEN,1998; FAO, 2002; BRASIL, 2008). No entanto, o período de ingestão necessário à obtenção de efeitos benéficos constitui uma incógnita e parece variar em função do hospedeiro e do micro-organismo utilizado.

\section{TABELA 1 - AGENTES ENCAPSULANTES UTILIZADOS EM MICRO-ORGANISMOS PROBIÓTICOS}

\begin{tabular}{cc}
\hline Micro-organismos encapsulados & Materiais aplicados \\
\hline B. bifidum & Carragena, alginato \\
B. infantis & Alginato, gelana, xantana, goma arábica, amido solúvel \\
B. longum & Carragena, alginato, goma locusta \\
B. lactis & Alginato, alginato de cálcio \\
B. breve & Proteínas do soro de leite, alginato + amido \\
B. pseudolongum & Ftalato de celulose, polímeros de acetato \\
L. lactis & Alginato,gelatina, tolueno 2,4 diisocianato \\
L. acidophillus & Alginato, alginato de cálcio, alginato + amido \\
L. plantarum & Alginato \\
L. delbrueckii sp. bulgaricus & Alginato, óleo de sesame, lauril sulfato de sódio \\
L. reuteri & Alginato + amido \\
L. rhamnosus & Alginato \\
\hline
\end{tabular}

Adaptado de SAKAR, 2010; SOCOL et al., 2010.

Os probióticos devem apresentar propriedades benéficas à saúde humana e animal. Dentre os benefícios atribuídos aos micro-organismos probióticos incluem-se: atividade antimicrobiana, redução do risco de doenças gastrointestinais, melhora no metabolismo da lactose, propriedades antimutagênicas e anticancerígenas, efeito hipocolesterolêmico, propriedades antidiarréicas, estimulação do sistema imunomodulador e melhora nas doenças inflamatórias intestinais (COLLINS, THORNTON e SULLIVAN,1998; OUWEHAND e SALMINEN,1998; GILL, DARRAGH e CROSS, 2001; ISOLAURI, SALMINEN e OUWEHAND, 2004; SHAH, 2007; RANADHEERA, BAINES e ADAMS, 2010). Alguns dos benefícios à saúde estão bem estabelecidos, enquanto outros apresentam resultados promissores em estudos in vitro ou em modelos animais, necessitando portanto de investigações mais aprofundadas. As linhagens probióticas cujos modos de ação já estão comprovados e bem fundamentados abrem perspectivas ao seu uso comercial em alimentos e fármacos. Essas linhagens são rapidamente difundidas e adicionadas a iogurtes, leites fermentados, queijos, sorvetes, sucos, cereais, associados ou não a compostos prebióticos para uso humano ou como complemento de ração animal (GAGGìA, MATTARELLI e BIAVATI, 2010; GRANATO et al., 2010; RIVERA-ESPINOZA e GALLARDO-NAVARRO, 2010).

Além da identificação da linhagem, da avaliação de segurança, resistência e viabilidade das culturas probióticas, a FAO/WHO recomenda que a rotulagem de alimentos probióticos contenha informações que esclareçam ao consumidor todos os benefícios alegados (FAO, 2002). Essas informações acompanham quaisquer produtos de forma geral, embora ocorram variações de acordo com a legislação de cada país. 


\section{MECANISMOS DE AÇÃO DE MICRO-ORGANISMOS PROBIÓTICOS SOBRE O HOSPEDEIRO}

Várias propriedades benéficas têm sido atribuídas aos micro-organismos probióticos. A comprovação desses efeitos com base em estudos in vitro e in vivo constitui premissa dos órgãos reguladores, tanto para caracterizar o micro-organismo probiótico como para regularizar seu uso em alimentos ou fármacos. A uniformização dessas avaliações também foi documentada por comitê científico conduzido pela FAO/WHO (2001) e trata apenas das alegações nutricionais e funcionais atribuídas aos micro-organismos probióticos.

\subsection{CAPACIDADE DE ADESÃO E INIBIÇÃO DE PATÓGENOS}

Para atingir o epitélio intestinal e chegar aos receptores que permitirão a adesão e colonização, os micro-organismos devem superar todas as etapas de passagem pelo TGI. Muitas bactérias probióticas têm a habilidade de aderir às superfícies da mucosa intestinal inibindo enteropatógenos (MEDELLIN-PEÑA et al., 2006; OHASHI e USHIDA, 2009). Os mecanismos de adesão são complexos e em geral associados à competição e à capacidade de comunicação desses micro-organismos via "crosstalking" ou "quorum sensing", embora os mecanismos envolvidos nessa "rede microbiana" não estejam bem esclarecidos (OUWEHAND et al., 2002; MEDELLIN-PEÑA et al., 2006).

Muitas linhagens probióticas podem aderir à camada mais externa do muco do epitélio intestinal ou às partículas de alimentos formando biofilme na sua superfície e impedindo a adesão de patógenos por exclusão competitiva. Esse conceito foi popularizado no início de 1970, quando se descobriu que a administração de micro-organismos de origem intestinal de frangos adultos conferia resistência a pintainhos contra infecção por Salmonella (NURMI, NUOTIO e SCHNEITZ, 1992).

A capacidade de adesão à mucosa intestinal, mediante bloqueio de sítios específicos nas células epiteliais foi observada em cultivo de células e posteriormente em estudos modelos in vivo. Em geral, os estudos destacam tanto a capacidade de adesão quanto incremento no sistema imunomodulador (WANG et al., 2009). Os probióticos também podem estabelecer relação simbiótica com o hospedeiro, criando nichos de competição por nutrientes que os favorece em detrimento de micro-organismos concorrentes (GUARNER e MALAGELADA, 2003). Além disso, alguns autores associam a inibição da aderência de enteropatógenos à indução da expressão de genes de mucina intestinal. Essa glicoproteína protegeria o TGI da ação de micro-organismos patogênicos (MACK et al., 1999), ou ainda a inibição de micro-organismos exógenos pela produção de substâncias antimicrobianas como ácidos orgânicos e bacteriocinas (GUARNER e MALAGELADA, 2003).

\subsection{AÇÃO EM DESORDENS INTESTINAIS}

Aintolerânciaà lactose resulta da deficiência primária e secundária da enzima $\beta$-galactosidase (lactase) e tem como consequência dor e distensão abdominal, flatulência e diarreia, geralmente associadas ao aumento da carga osmótica no intestino delgado e secreção de líquido nas fezes (SHERMAK et al., 1995). Os probióticos são frequentemente relacionados à melhor absorção da lactose nesses indivíduos devido à presença da lactase bacteriana que auxilia a clivagem da lactose antes que ela atinja o cólon, levando a posterior absorção sob a forma de monossacarídeos (DEWIT, POCHART E DESJEUX, 1988).

Disfunções intestinais com irritações da mucosa, como ocorrem na doença de Crohn, colites ou síndrome do intestino irritado, frequentemente ocasionam diarreias e vômitos. O tratamento dessas doenças, associado ao uso de probióticos, minimiza os efeitos e diminui o período de diarreias (GUARINO et al., 1997). O efeito, em geral, é atribuído à melhoria no sistema imunomodulador do hospedeiro (WALKER et al., 2006). Em resposta a toxinas de Clostridium difficile, a ingestão de Saccharomyces boulardii levou ao aumento dos anticorpos IgA e IgG. Do mesmo modo, indivíduos 
com gastroenterite rotaviral tiveram aumento da produção de IgA após a ingestão de $L$. rhamnosus GG (WALKER, 2008).

A presença de Helicobacter pylori está associada a úlceras gástricas e ocorrência de câncer. Embora seu papel na etiologia dessas doenças não esteja elucidado, o efeito de probióticos sobre $H$. pylori foi evidenciado em estudos in vitro e envolvendo modelos animais. Tais estudos comprovaram que tanto substâncias antimicrobianas de Lactobacillus quanto o incremento do sistema imunomodulador do hospedeiro inibem o crescimento e adesão desse patógeno (KUMAR et al., 2010).

A imaturidade da mucosa do intestino delgado em bebês prematuros em contato com alguns micro-organismos patogênicos desencadeia resposta inflamatória, podendo causar a necrose dos tecidos (WALKER, 2008). Estudo clínico, envolvendo recém-nascidos prematuros, demonstrou que a introdução dos probióticos Lactobacillus lactis e Bifidobacterium infantis pode prevenir a expressão dessa inflamação (DESHPANDE, RAO e PATOLE, 2007).

\subsection{EFEITO SOBRE O SISTEMA IMUNOMODULADOR}

Muitos estudos indicam que a microbiota intestinal autóctone representa importante modulador da homeostase intestinal (OUWEHAND e SALMINEN, 1998; MEDINAet al., 2007). O efeito da interação entre os micro-organismos e o TGI foi observado em animais mantidos em ambientes isentos de contaminação e posteriormente colonizados com probióticos. Imediatamente após a exposição aos micro-organismos do lúmen, o número de linfócitos intra-epiteliais aumenta muito. Os centros germinativos com células produtoras de imunoglobulinas surgem rapidamente nos folículos e na lâmina própria e as concentrações de imunoglobulinas aumentam substancialmente no plasma (GUARNER e MALAGELADA, 2003). Esse efeito também está relacionado à capacidade de microorganismos probióticos interagirem com folículos linfoides intestinais (placas de Peyer) estimulando a resposta imune das mucosas por ação das células $B$, produtoras de lgA, e a migração de linfócitos ou células T do intestino, um dos principais responsáveis pela imunidade celular (WALKER et al., 2006).

Em células epiteliais, endoteliais e linfoide de eucariotos, os receptores toll-like (TLR), que têm papel chave no sistema imunológico, podem interagir com padrões moleculares de patógenos e bactérias comensais desencadeando respostas fisiológicas. Em geral, esse mecanismo está associado à modulação da resposta inata ou adquirida do sistema imunológico (GILL, DARRAGH e CROSS, 2001). Em estudos in vivo e in vitro, envolvendo a suplementação da dieta de camundogos saudáveis com Lactobacillus rhamnosus HN001 e DR20, L. acidophilus HN017 e B. lactis HN019 e DR10 houve aumento da imunidade natural e adquirida (AKIRA, TAKEDA e KAISHO, 2001; GILL, DARRAGH e CROSS, 2001). Em investigação com crianças alérgicas a leite de vaca, em dieta suplementada com $L$. rhamnosus $G G$, foram detectados maior dosagem de imunoglobulina IgA e menor nível do fator de necrose tumoral alfa (TNF- $\alpha$ ) em comparação com o grupo que recebeu placebo (ISOLAURI, SALMINEN e OUWEHAND, 2004).

Os probióticos também favorecem a atividade fagocítica inespecífica dos macrófagos alveolares por ação sistêmica, devido à secreção de mediadores que estimulam o sistema imune (CROSS, 2002). Além disso, a maturação de células dendríticas e a liberação de citocinas desencadeiam a conversão de células T helper, componente importante na prevenção de doenças (WALKER, 2008). Medina et al. (2007) avaliaram a capacidade de diferentes linhagens de B.longum induzirem a produção de citocinas por células sanguíneas. Todas as linhagens induziram padrões de citocinas específicas, sugerindo o envolvimento dessas proteínas na emissão de sinais entre as células durante o desencadeamento de respostas imunes.

A associação do consumo de probiótico a incrementos do sistema imunomodulador têm sido bem comprovada por estudos clínicos, e há consenso quanto ao equilíbrio da microbiota intestinal e esses efeitos. Em contrapartida, o desequílibrio dessa interação está diretamente correlacionada à disbiose e a ocorrência de doenças. 


\subsection{PROBIÓTICOS NA PREVENÇÃO DE DESORDENS CELULARES}

O papel de micro-organismos probióticos na prevenção de câncer de cólon ainda não está bem esclarecido. No entanto, o uso de probióticos foi relacionado à redução da atividade de enzimas fecais, conhecidas pela produção de compostos genotóxicos que atuam como iniciadores de tumores em seres humanos (GUARNER e MALAGELADA, 2003; SAIKALI et al., 2004; PICARD et al., 2005). Existem evidências de que a microbiota intestinal normal pode influenciar a carcinogênese pela produção de enzimas que transformam pró-carcinogênicos em compostos ativos, geralmente mais tóxicos que o composto de origem (PICARD et al., 2005).

Em estudo que investigou a eficácia de bactérias ácido láticas (BAL) contra 2-amino-3metilimidazol [4,5-f] quinolina, classe de aminas heterocíclicas, foi demonstrado que oito Lactobacillus, dentre 76 BAL avaliadas, apresentaram efeito antimutagênico (TAVAN et al., 2002). Esses efeitos, também podem ser associados a prebióticos que são capazes de absorver e desintoxicar tais compostos (WOLLOWSKI, RECHKEMMER e POOL-ZOBEL, 2001).

\subsection{EFEITO DOS PROBIÓTICOS NAS DOENÇAS CARDIOVASCULARES}

Os probióticos exercem efeito benéfico sobre algumas desordens metabólicas como a hipertensão e a hipercolesterolemia (LYE et al., 2009). A síntese do colesterol ocorre principalmente no intestino e, dessa maneira, a microbiota intestinal promove efeitos no metabolismo lipídico, diminuindo os níveis do colesterol sanguíneo e aumentando a resistência da lipoproteína de baixa densidade (LDL) à oxidação, levando à redução da pressão arterial (GOEL et al., 2006).

Experimentos com lactobacilos ou bifidobactérias evidenciaram a diminuição dos níveis de colesterol sérico total e de LDL, além do aumento da lipoproteína de alta densidade (HDL) (LIONG e SHAH, 2004). Os mecanismos propostos para esses efeitos estão associados à assimilação do colesterol durante o crescimento bacteriano ou a ligação do colesterol à superfície da parede celular dessas bactérias (LIONG e SHAH, 2004). Além disso, há hipóteses relacionadas à capacidade de alguns micro-organismos probióticos produzirem hidrolases que desconjugam ácidos biliares, que por sua vez são reabsorvidos com menor eficiência quando comparados aos ácidos conjugados, resultando em aumento da sua excreção nas fezes. Como o colesterol é precursor da síntese de ácidos biliares, conforme aumenta a demanda desses ácidos ocorre redução das concentrações de colesterol plasmático (BEGLEY, HILL e GAHAN, 2006).

Os avanços no estudo da microbiota intestinal também identificam esse ambiente como um dos fatores que modulam o metabolismo lipídico, razão da associação do equilíbrio microbiano intestinal à possibilidade de redução da obesidade (RASTMANESH, 2011).

\section{CONSIDERAÇÕES FINAIS}

Cada indivíduo possui metabolismo fisiológico e microbiota intestinal únicos, de forma que selecionar uma linhagem para atender às necessidades específicas de determinado público, bem como compreender os mecanismos de ação desses micro-organismos no hospedeiro, poderá incrementar a eficácia dos probióticos veiculados em alimentos. A busca dessas linhagens e o estudo dos seus efeitos representam um dos grandes desafios propostos aos cientistas e às indústrias de alimentos.

\section{ABSTRACT}

\section{PROBIOTIC MICROORGANISMS: THE CHARACTERIZATION OF STRAINS AND ITS EFFECTS IN THE HOST}

This review aims to disclose the safety criteria for characterization of probiotic strains, approached and discussed by the agency regulatory such as the United Nations Food and Agriculture Organization and World Health Organization. It was also discussed the importance of probiotic strains and the mechanisms of action currently attributed to microrganisms on the host health. Our purpose is that this material can also be 
used as a reference to standardize the characterization of probiotic strains applied in food industry. The scientific community and industries that uses probiotics in their products aim to select specific strains to the physiological needs of the host. Therefore, the standardization of these strains, the conduct of clinical trials as well as understanding the phenomena involved in probiotic-host interaction have become substantial importance.

KEY-WORDS: PROBIOTICS STRAINS; INTESTINAL MICROBIOTA; FUNCTIONAL FOODS.

\section{REFERÊNCIAS}

1 ADAMS, M.R.; MARTEAU, P. On the safety of lactic acid bacteria. International Journal of Food Microbiology, v. 27, p. 263-264,1995.

2 AKIRA, S.; TAKEDA, K.; KAISHO, T. Toll-like receptors: critical proteins linking innate and acquired immunity. Nature Immunology, v.2, p. 675-680, 2001.

3 BEGLEY, M.; HILL, C.; GAHAN, C.G.M. Bile salt hydrolase activity in probiotics. Applied and Environmental Microbiology, v. 72, n.3, p. 1729-1738, 2006.

4 BRASIL. Agência Nacional de Vigilância Sanitária (ANVISA). Resolução RDC no 278, de 22 de setembro de 2005 , atualizada em julho de 2008. Legislação para alimentos com alegações de propriedades funcionais e ou de saúde, novos alimentos/ingredientes, substâncias bioativas e probióticos. Disponível em: http://www.anvisa.gov.br/ alimentos/comissoes/tecno_lista_alega.htm. Acesso em: 20 de dez. de 2011.

5 CHAMPAGNE, C.P.; FUSTIER, P. Microencapsulation for the improved delivery of bioactive compounds into foods. Current Opinion in Biotechnology, v.18, p. 184-190, 2007.

6 COLLINS, J.K.; THORNTON, G.; SULLIVAN, G.O. Selection of probiotic strains for human applications. International Dairy Journal, v. 8, p. 487-490, 1998.

7 CONWAY, P.L.; GORGABCH, S.L.; GOLDIN, B.R. Survival of lactic acid bacteria in the human stomach and adhesion to intestinal cells. Journal of Dairy Science, v. 70, p. 1- 12, 1987.

8 COURVALIN, P. Antibiotic resistance: the pros and cons of probiotics. Digestive and Liver Disease, v. 38, Suppl. 2, p. S261-S265, 2006.

9 CROSS, M.L. Microbes versus microbes: immune signals generated by probiotic lactobacilli and their role in protection against microbial pathogens. FEMS Immunology and Medical Microbiology, v.34, n. 4, p.245-253, 2002.

10 DAVE, R.I.; SHAH, N.P. Ingredient supplementation effects on viability of probiotic bacteria in yogurt. Journal of Dairy Science, v. 81, n. 11, p. 2804-2816, 1998.

11 DEL PIANO, M.; MORELLI, L.; STROZZI, G.P.; ALLESINA, M.; BARBA, S.; DEIDDA, F.; LORENZINI, P.; BALLARE, M.; MONTINO, F.; ORSELLO, M.; SARTORI, M.; GARELLO, E.; CARMAGNOLA, S.; PAGLIARULO, M.; CAPURSO, L. Probiotics: from research to consumer. Digestive and Liver Disease, v.38, Suppl. 2, p. 248-255, 2006.

12 DEL PIANO, M.; STROZZI, P.; BARBA, M.; ALLESINA, S.; DEIDDA, F.; LORENZINI, P.; MORELLI, L.; CARMAGNOLA, S.; PAGLIARULO, M.; BALZARINI, M.; BALLARE, M.; ORSELLO, M.; MONTINO, F.; SARTORI, M.; GARELLO, E.; CAPURSO, L. In vitro sensitivity of probiotics to human pancreatic juice. Journal of Clinical Gastroenterology, v. 42, n. 8, p.170-173, 2008.

13 DESHPANDE, G.; RAO, S.; PATOLE, S. Probiotics for prevention of necrotizing enterocolitis in preterm neonates with very low birthweight: a systematic review of randomized controlled trials. Lancet, v. 369, p.1614-1620, 2007.

14 DEWIT, O.; POCHART, P.; DESJEUX, J.F. Breath hydrogen concentration and plasma glucose, insulin and free fatty acid levels after lactose, milk, fresh or heated yogurt ingestion by healthy young adults with or without lactose malabsorption. Nutrition, v. 4, p. 131-136, 1988.

15 DOLEYRES, Y.; PAQUIN, C.; LE ROY, M.; LACROIX, C. Bifidobacterium longum ATCC 15707 cell production during free- and immobilized-cell cultures in MRS-whey permeate medium. Applied Microbiology and Biotechnology, v. 60, p.168-173, 2002.

16 FAO. Food and Agriculture Organization of the United Nations. Guidelines for the evaluation of probiotics in food. Ontario, Canada, 2002. (Report of a joint FAO/WHO Working Group on drafting guidelines for the evaluation of probiotics in food).

17 FAO. Food and Agriculture Organization of the United Nations. Health and nutritional properties of probiotics in food including powder milk with live lactic acid bacteria. Cordoba, Argentina, 2001. (Report of a Joint FAO-WHO Expert on evaluation of health and nutritional properties of probiotics in food including powder milk with live lactic acid bacteria).

18 FLOCH, M.H. Bile salts, intestinal microflora and enterohepatic circulation. Digestive and Liver Disease, v. 34,Supl. 2, p. 554-57, 2002. 
19 GAgGìA, F.; MATTARELLI, P.; BIAVATI. B. Probiotics and prebiotics in animal feeding for safe food production. International Journal of Food Microbiology, v. 141, p. S15-S28, 2010.

20 GILL, H.S.; DARRAGH, A.J.; CROSS, M.L. Optimizing immunity and gut function in the elderly. The Journal of Nutrition Health \& Aging, v. 5, n. 2, p. 80-91, 2001.

21 GOEL, A.K.; DILBAGHI, N.; KAMBOJ, D.V.; SINGH, L. Probiotics: microbial therapy for health modulation. Defence Science Journal, v. 56, p. 513-529, 2006.

22 GRANATO, D.; BRANCO, G.F.; CRUZ, A.G.; FARIA, J.A.F.; SHAH, N.P. Probiotic dairy products as functional foods. Comprehensive Reviews in Food Science and Food Safety, v. 9, p. 455-470, 2010.

23 GUARINO, A.; CANANI, R.B.; SPAGNUOLO, M.I.; ALBANO, F.; DI BENEDETTO, L. Oral bacterial therapy reduces the duration of symptoms and of viral excretion in children with mild diarrhea. Journal of Pediatric Gastroenterology and Nutrition, v. 25, n. 5, p. 516-519, 1997.

24 GUARNER, F.; MALANGELADA, J.R. Gut flora in health and disease. Lancet, v. 361, p. 512-519, 2003.

25 GUEIMONDE, M.; SALMINEN, S. New methods for selecting and evaluating probiotics. Digestive and Liver Disease, v. 38, Suppl. 2, p. 242-247, 2006.

26 GUERGOLETO, K.B.; MAGNANI, M.; SAN MARTIN, J.; ANDRADE, C.G.T.J.; GARCIA, S. Survival of Lactobacillus casei (LC-1) adhered to prebiotic vegetal fibers. Innovative Food Science \& Emerging Technologies, v.11, n.2, p.415-421, 2010.

27 ISOLAURI, E.; SALMINEN, S.; OUWEH, A.C. Probiotics. Best Practice \& Research Clinical Gastroenterology, v. 18, n. 2, p. 299-313, 2004.

28 JANKOVIC, I.; SYBESMA, W.; PHOTHIRATH, P.; ANANTA, E.; MERCENIER, A. Application of probiotics in food productos - challenges and new approaches. Current Opinion in Biotechnology, v. 21, p. 175-181, 2010.

29 KAWASAKI, S; MIMURA, T.; SATOH, T.; TAKEDA, K.; NIIMURA, Y. Response of the microaerophilic Bifidobacterium species, B. boum and B. thermophilum, to oxygen. Applied and Environmental Microbiology, v.72, p. 6854-6858, 2006.

30 KUMAR, V.P.; PRASANTHI, S.; ROHINI, A.; GANDHI, K. S.; MANJARI, A.D. Probiotics in improving the standards of human life. Developmental Microbiology and Molecular Biology, v. 1, n.1, p. 13-19, 2010.

31 LACROIX, C.; YILDIRIM, S. Fermentation technologies for the production of probiotics with high viability and functionality, Current Opinion in Biotechnology, v.18, p.176-183, 2007.

32 LANKAPUTHRA, W.E.V.; SHAH, N.P. Survival of Lactobacillus acidophilus and Bifidobacterium spp. in the presence of acid and bile salts. Cultured Dairy Products Journal, v. 30, p. 2-7, 1995.

33 LIONG, M.T.; SHAH, N.P. Acid and bile tolerance and the cholesterol removal ability of bifidobacteria strains. Bioscience Microflora, v. 24, n. 1, p. 1-10, 2004.

34 LYE, H.S.; KUAN, C.Y.; EWE, J.A.; FUNG, W.Y.; LIONG, M.T. The improvement of hypertension by probiotics: effects on cholesterol, diabetes, renin, and phytoestrogens. International Journal Molecular Science, v. 10, p. 3755-3775, 2009.

35 MACK, D.R.; MICHAIL, S.; WEI, S.; MCDOUGALL, L.; HOLLINGSWORTH, M.A. Probiotics inhibit enteropathogenic E. coli adherence in vitro by inducing intestinal mucin gene expression. American Journal of Physiology, v. 276, p. 941950, 1999.

36 MEDELLIN-PEÑA, M.J.; WANG, H.; JOHNSON, R.; ANAND, S.; GRIFFITHS, M.W. Probiotics affect virulence-related gene expression in Escherichia coli O157:H7. Applied and Environmental Microbiology, v. 73, n.13, p. 4259-4267, 2007.

37 MEDINA, M.; IZQUIERDO, E.; ENNAHAR, S.; SANZ, Y. Differential immunomodulatory properties of Bifidobacterium logum strains: relevance to probiotic selection and clinical applications. Clinical and Experimental Immunology, v.150, p. 531-538, 2007.

38 NURMI, E.; NUOTIO, L.; SCHNEITZ, C. The competitive exclusion concept: development and future. International Journal of Food Microbiology, v. 15, p. 237-240, 1992.

39 Organisation for Economic Co-operation and Development (OECD). Guideline for the testing of chemicals, $\mathbf{n}$. 408 , 1998. Disponível em: http://www.ask-force.org/web/OECD/OECD-Repeated-90day-on-Rodents-408-1998.pdf. Acesso em: 24 de março de 2011.

40 OHASHI, Y.; USHIDA, K. Health-beneficial effects of probiotics: its mode of action. Animal Science Journal, v. 80, p.361$371,2009$.

41 OUWEHAND A.C.; SALMINEN, S.J. The health effects of cultured milk products with viable and non-viable bacteria. 
International Dairy Journal, v. 8, p. 749-758, 1998.

42 OUWEHAND, A.C.; SALMINEN, S.; TÖLKÖ, S.; ROBERTS, P.; OVASKA, J.; SALMINEN, E. Resected human colonic tissue: new model for characterizing adhesion of lactic acid bacteria. Clinical and Diagnostic Laboratory Immunology. v. 9, n. 1, p.184-186, 2002.

43 PICARD, C.; FIORAMONTI, J.; FRANCOIS, A.; ROBINSON, T.; NEANT, F.; MATUCHANSKY, C. Bifidobacteria as probiotic agents - physiological effects and clinical benefits. Alimentary Pharmacology \& Therapeutics, v. 22, p. 495$512,2005$.

44 RANADHEERA, R.D.C.S.; BAINES, S.K.; ADAMS, M.C. Importance of food in probiotic efficacy. Food Research International, v. 43, p.1-7, 2010.

45 RASTMANESH, R. High polyphenol, low probiotic diet for weight loss because of intestinal microbiota interaction. Chemico-Biological Interactions, v. 189, p.1-8, 2011.

46 RIVERA-ESPINOZA, Y.; GALLARDO-NAVARRO, Y. Non-dairy probiotic products. Food Microbiology, v. 27, p.1-11, 2010.

47 SAARELA, M.; RANTALA, M.; HALLAMAA, K.; NOHYNEK, L.; VIRKAJARVI, I.; MÄTTÖ, J. Stationary-phase acid and heat treatments for improvement of the viability of probiotic lactobacilli and bifidobacteria. Journal of Applied Microbiology, v. 96, p. $1205-1214,2004$.

48 SAIKALI, J.; PICARD, C.; FREITAS, M.; HOLT, P. Fermented milks, probiotic cultures, and colon cancer. Nutrition and Cancer, v. 49, p.14-24, 2004.

49 SARKAR, S. Approaches for enhancing the viability of probiotics: a review. British Food Journal, v. 112, n.4, p.329-349, 2010.

50 SARKAR, S.; MISRA, A.K. Implication LP-system on the manufacture of fermented milk products. Indian Journal of Dairy Science, v. 47, p.133-139, 1994.

51 SAVINI, M.; CECCHINI, C.; VERDENELLI, M.C.; SILVI, S.; ORPIANESI, C.; CRESCI, A. Pilot-scale production and viability analysis of freeze-dried probiotic bacteria using different protective agents. Nutrients, v. 2, p.330-339, 2010.

52 SCHMIDT, G.; ZINK, R. Basic features of the stress response in three species of bifidobacteria: B. longum, B. adolescentis, and B. breve. International Journal of Food Microbiology, v. 55, p. 41-45, 2000.

$53 \mathrm{SHAH}$, N.P. Functional cultures and health benefits. International of Dairy Journal, v. 17, p. 1262-1277, 2007.

54 SHERMAK, M.A.; SAAVEDRA, J.M.; JACKSON, T.L.; HUANG, S.S.; BAYLESS, T.M.; PERMAN, J.A. Effect of yogurt on symptoms and kinetics of hydrogen production in lactose malabsorbing children. American Journal of Clinical Nutrition, v. 62, p.1003-1006, 1995.

55 SOCOL, C.R.; VANDENBERGHE, L.P.S.; SPIER, M.R.; MEDEIROS, A.B.P.; YAMAGUISHI, C.T.; LINDNER, J.D.; PANDEY, A.; SOCCOL, V.T. The potential of probiotics. Food Technology and Biotechnology, v.48, n.4, p.413-434, 2010.

56 TALWALKAR, A.; KAILASAPATHY, K. Effect of microencapsulation on oxygen toxicity in probiotic bacteria. Australian Journal of Dairy Technology, v.58, p.36-39, 2003.

57 TAVAN, E.; CAYUELA, C.; ANTOINE, J.M.; CASSAND, P. Antimutagenic activities of various lactic acid bacteria against food mutagens: heterocyclic amines. Journal of Dairy Research, v.69, p.335-341, 2002.

58 WALKER, W.A. Mechanisms of action of probiotics. Clinical Infectious Diseases, v.46, p.87-91, 2008.

59 WALKER, W.A.; GOULET, O.; MORELLI, L.O.; ANTOINE, J.M. Progress in the science of probiotics. European Journal of Nutrition, v.45, Suppl. 1, p.1-18, 2006

60 WANG, B.; LI, J.; LI, Q.; ZHANG, H.; LI, N. Isolation of adhesive strains and evaluation of the colonization and immune response by Lactobacillus plantarum L2 in the rat gastrointestinal tract. International Journal of Food Microbiology, $v$. 132, p.59-66, 2009.

61 WOLLOWSKI, I.; RECHKEMMER, G.; POOL-ZOBEL, B.L. Protective role of probiotics and prebiotics in colon cancer. The American Journal of Clinical Nutrition, v.73, p. 451-455, 2001.

\section{AGRADECIMENTOS}

Os autores agradecem ao Conselho Nacional de Desenvolvimento Científico e Tecnológico (CNPq), processo: 140352/2008-2, pela concessão da bolsa de estudos à GNC. 